go against the Euratom treaty, the commission has to communicate its observations to the Euratom states concerned within a month. This seems to be what has now happened. Although there is no official news of what the objections are, one possibility is that the commission is worried that Britain would be able to prevent members of the Community not in the centrifuge collaboration from access to the uranium. Under the draft agreement there is to be a joint committee with members from Britain, the Netherlands and West Germany to deal with relationships with other states, but the commission must feel that this is not enough to safeguard the interests of the Community as a whole.

The point of the centrifuge method is that it ought to be possible to produce enriched uranium at a price comparable with what the US Atomic Energy Commission charges-\$26 per kg of separative work. Precisely what the selling price is likely to be has not been made known, and all that Mr Benn will say is that it will be competitive with the American product. At present, all the members of the European Community are supplied from the United States, with the exception of France which operates a gaseous diffusion plant. Part of the trouble seems to be that the Community is at present discussing arrangements for the supply of enriched uranium in the future and is bound to be disturbed with a fait accompli by two of its members.

Although the centrifuge has small beginnings-an aim of 50 tonnes of separative work in 1972-what the collaboration is working towards is the 15,000 tonnes which is the predicted European requirement by 1980 . With this target in view, the commission is hardly likely to torpedo the project once there is assurance that it can be integrated into a European framework, and the Belgians and Italians have already been interested in joining. Once again, like the agreement to rescue Euratom early in December (see Nature, 224, $1047 ; 1969)$, the move is as likely as not a political decision, and is another indication that Europe's nuclear policy is hardly likely to be settled until the question of British entry to the Community is decided one way or the other.

\section{CERN ACCELERATOR}

\section{When is the Last Bus?}

Prospects for the proposed $300 \mathrm{GeV}$ CERN accelerator are starting to look rather bleak. The West German Government finally called off the ministerial meeting scheduled to be held in Geneva last week after a period of tough talking between the German and Belgian Governments over the siting of the accelerator. Little progress seems to have been made in quelling the West German Government's conviction that it should now put pressure on its European partners for a fairer deal in joint scientific ventures, and there seems little chance that any of the other five participants to the project will allow the siting of the project to be determined by anything resembling strong-arm tactics.

One theory, which has made its way into print in the Belgian newspaper Le Soir, is that the West German Government has been re-evaluating the project and has found it too expensive. This would explain the odd timing of the announcement that the Federal Government will reconsider its participation if the West German site near Munster was not selected at the December meeting of the CERN Council. Some doubts have, in any case, been expressed about the suitability of the German site. Another view is that the French Government has decided to back the Belgian site in return for the purchase of Mirage aircraft by the Belgian Government, but in such a fluid situation the wildest speculations can easily gain a hold.

In one sense the British Government's decision to steer clear of the project may be held as the primary cause of the impasse, placing a heavier financial burden on each of the other governments and so elevating the importance of the location. In another sense, however, British participation would have added another arm to the multilateral tug of war, and the British Government may be feeling that it made the best decision after all.

\section{FABIAN SOCIETY \\ Priorifies in Education}

\section{by our Education Correspondent}

THE Department of Education and Science should publish a green paper to stimulate discussion about the possibilities that exist at every level of education and their financial consequences. This, according to a pamphlet published by the Fabian Society, would provide a basis for informed discussion about priorities in education, and would help in the formulation of a national plan on the subject. The authors of the pamphlet strongly criticize the British Government for attacking the problem of expansion in education on a piecemeal basis and, in turn, they call for rapid expansion of nursery education and for more provision for further education of students leaving school at the age of sixteen.

The pamphlet is a brave attempt to assess priorities in education, and it also attempts to calculate the costs of alternative policies. The authors argue that if existing policies are continued, the share of the gross national product devoted to education will grow from the present $5 \cdot 7$ per cent to about 8 per cent in 1980 , but if the policies that they recommend are adopted, then the figure would be about 9 per cent. This estimate is based on proposals for universal nursery education, the employment of teachers' aides in primary schools, as suggested in the Plowden Report, fully comprehensive education in secondary schools, a major expansion of further education and reorganization of higher education.

As far as higher education is concerned, the authors of the pamphlet argue that the Robbins committee grossly underestimated the likely demand for higher education. The major problem, they argue, is to increase the number of students and still maintain the existing standards of building and the staff/student ratio. The pamphlet calls for a greater variety of full and part time courses in the universities, and suggests that the main developments of this kind are at present occurring in the polytechnics. Boosting the polytechnics is therefore right in the short term, but "over a period of time, the separation of institutions of higher education into distinct classes could have most undesirable results". The authors argue that because the polytechnics devote a lower proportion of their resources to research, they offer fewer senior posts, and that the facilities provided for their students are inferior to those provided by the universities. If this 
situation persists, polytechnics will be nothing more than second class institutions, and the part they play will be devalued with them. The authors of the pamphlet therefore believe that "in due course federal structures should be developed, each of which should embrace all the institutions of higher education within its area".

The authors of the pamphlet were Professor H. D. Hughes, principal of Ruskin College, Oxford, Caroline Benn, editor of Comprehensive Education, Tessa Blackstone, David Downes and Howard Glennerster, lecturers at the London School of Economics, and Stephen Hatch from Brunel University.

\section{LONDON UNIVERSITY}

\section{Taking the Strain}

\section{by our Education Correspondent}

IF the latest projections of student numbers in 1980 prove to be correct, the University of London external degree system will break down. The government and administration of the university will also be severely strained. These fears have prompted the setting up of a joint committee of the university and the Universities Grants Committee to look at the future of the University of London as a federal institution. The committee of inquiry will have sweeping terms of reference, but it will concentrate mainly on the organs of government of the university-the Senate and its standing committecs, the convocation and the courtand it will also consider how staff and students can participate in the decision-making process.

The university Senate said last week that since 1962 its policy has been not to increase its external examining commitments, but despite the advent of the Council for National Academic Awards, the number of external degree students has increased by almost 50 per cent during the last eight years, and the external examining resources of the university are already severely strained. The committee of enquiry will therefore look at the relationship between the internal and external degree systems.

Such a committee is not without precedent. In 1963, the Robbins Committee said that the University of London has problems which call for investigation and remedy, and, if those problems could not bo resolved internally, they "should be the subject of independent inquiry". The university set up a steering committee to consider the implications of the report, and since then, the Senate says, the academic organization of the university has been completely reshaped. But there are still problems which require outside help, and the University Grants Committee has agreed to cooperate in establishing the committee of inquiry.

\section{WOLFSON FOUNDATION}

\section{More Grants to Universities}

The Wolfson Foundation is to make further grants for university research projects likely to benefit British industry. In November 1968, the foundation supported fifteen projects to the tune of about \&l million (Nature, 220, 1165; December 21, 1968) and General A. R. Leakey, the foundation's director, has indicated that a similar sum may be made available at the end of this year. The total value of the grants will, however, depend on the applications received from the universities.

The foundation's last spending spree in the universities attracted more than 150 applicants, and the fifteen chosen for support make an impressive list. It seems that the Wolfson Foundation has not found itself inundated with applications which have been turned down by other grant awarding bodies and, indeed, many academics may even apply to the foundation in preference to the research councils because it places less restriction on the way the grant is spent. Among the projects already being supported are several liaison units between university and industry. For example, the Wolfson Microelectronics Liaison Unit at Edinburgh, the Wolfson Industrial Unit at Southampton and the Wolfson Bioanalytical Centre at the University of Surrey are all hoping to undertake direct consultancy work for industry, the intention being to earn money for research which may have immediate industrial application. Other projects chosen for support also have potential industrial applications; for example, Birmingham is developing a high-speed press driven by combustion of hydrocarbon fuels and the University of Wales Institute of Science and Technology is setting up a centre for the technology of soft magnetic materials. Grants which will be awarded this year will probably support similar projects, and applications must be made before July.

\section{INFRARED ASTRONOMY \\ Latest Light Bucket Ready}

\author{
by our Astronomy Correspondent
}

ONe problem facing Professor Jim Ring this week has been how to get a 40 -inch infrared telescope out of the cellar of 10 Prince's Gardens, the terrace-house home of the infrared astronomy group at Imperial College, London. The telescope is the latest step in a progression which people are hoping will lead one day to the building of a 120-inch infrared telescope for the consortium of British universities which have banded together to promote infrared astronomy. But the 40 -inch telescope is an Imperial College venture, built

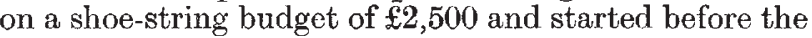
Science Research Council a year ago announced the award of $£ 27,000$ to the Imperial College group. This grant is earmarked for a 60 -inch telescope, the next step in the path to the 120 -inch, now past the design stage and awaiting detailed drawings before the parts go out to tender in April or May.

Infrared telescopes, more properly called flux collectors-light buckets in the language of astronomyare cheap compared with similar equipment for the visible spectrum because the optics do not have to be so accurate. This leaves the way open for unusual optical systems, and the 40-inch has a novel design even for infrared telescopes. Light is directed on to the 40 -inch paraboloid by a glass flat about 60 inches across. Because of the problem of supporting a sheet of glass this size, the flat is made up of a circle of six hexagons with a hole where the seventh hexagon in the pattern ought to be. The paraboloid converges the beam to a focus through the hole, and this is where the detectors will be fixed.

The next step is to transfer the telescope from the basement workshop at Prince's Gardens, where it was 